\title{
Identification of demographic factors and health problems that affect the acceptance of disease and health behaviors of patients with osteoarthritis
}

\author{
Matylda Sierakowska ${ }^{\text {Corresp.. }}{ }^{1}$ ， Izabela Wysocka - Skurska ${ }^{2}$, Wojciech Kułak ${ }^{3}$ \\ 1 Department of Integrated Medical Care, Medical University of Bialystok, Bialystok, Poland \\ 2 Department of Rheumatology and Internal Diseases, University Hospital in Bialystok, Bialystok, Poland \\ 3 Medical University of Bialystok, Clinic Rehabilitation Center for Children with Early Help Disabled Children "Give a Chance", Bialystok, Poland \\ Corresponding Author: Matylda Sierakowska \\ Email address: matyldasierakowska@gmail.com
}

INTRODUCTION Osteoarthritis (OA) is one of the most common causes of musculoskeletal system's ailments. In the prevention of the disease and in its comprehensive treatment, it is proper health-related behavior that becomes an extremely important factor for the maintaining of optimal health condition. THE AIM OF THE STUDY is to assess the relationship between the reported pain and the disability level and the health-related behaviors undertaken by OA patients as well as their acceptance of the disease. MATERIALS / METHODS: The study group consisted of 198 patients with diagnosed OA, according to ACR criteria (1988). The method used in the study was a Pain VAS (0-10), Health Assessment Questionnaire Disability Index (HAQ DI 0-3), Acceptance of Illness Scale (AIS 8-40) and Health and Behavior Inventory (IZZ 24-120). RESULTS: The average age among respondents with OA has been 59.16 years of age $( \pm 15.87)$, duration of disease 5.5 years $( \pm 4.32)$. Experienced pain, both during movement $(r=0.319, p<0.001)$ and at rest $(r=0.375, p<0.001)$ correlated positively with physical disability (HAQ DI). Studies indicated a positive linear correlation between the age and physical disability $\left(r_{s}=0.200\right.$, $p=0.005)$. Acceptance of the disease (AIS) depends mostly on age $(r=-0.325, p<0.001)$, on pain in motion $(r=-0.209, p<0.001)$ and at rest $(r=-0.218, p<0.001)$ and on the disability levels $(r=-0.353, p<0.001)$. Analysis of the health-related behaviors (IZZ) indicates the average severity of declared behavior a statistically significant with physical disability (HAQ DI) ( $p=0.029)$. CONCLUSIONS: With age and progressive levels of disability as well as with the severity of pain, the acceptance of illness is reduced significantly. The progressive levels of disability and younger age of the respondents motivate them to engage in health beneficial behavior. 
1 Identification of demographic factors and health problems that affect the

2 acceptance of disease and health behaviors of patients with osteoarthritis 3

4 Acceptance and health behaviors in OA

5

6 Authors

7 Matylda Sierakowska ${ }^{1}$, Izabela Wysocka - Skurska² ${ }^{2}$, Wojciech Kułak ${ }^{3}$

8

\section{Institutional affiliations}

$10{ }^{1}$ Department of Integrated Medical Care, Medical University of Bialystok, Poland

11 2Department of Rheumatology and Internal Diseases, University Hospital in Bialystok, Poland

$12{ }^{3}$ Clinic Rehabilitation Center for Children with Early Help Disabled Children "Give a Chance",

13 Medical University of Bialystok, Poland

16 Corresponding author

17 Matylda Sierakowska, Department of Integrated Care Medical, Medical University of Bialystok,

18 7a Maria Sklodowska-Curie Street, 15-096 Bialystok, Poland

19 Telephone: (48-85) 6865102, E-mail: matyldasierakowska@gmail.com 


\section{ABSTRACT}

24 25

INTRODUCTION Osteoarthritis (OA) is one of the most common causes of musculoskeletal system's ailments. In the prevention of the disease and in its comprehensive treatment, it is proper health-related behavior that becomes an extremely important factor for the maintaining of optimal health condition. THE AIM OF THE STUDY is to assess the relationship between the reported pain and the disability level and the health-related behaviors undertaken by OA patients as well as their acceptance of the disease. MATERIALS / METHODS: The study group consisted of 198 patients with diagnosed OA, according to ACR criteria (1988). The method used in the study was a Pain VAS (0-10), Health Assessment Questionnaire Disability Index (HAQ DI 0-3), Acceptance of Illness Scale (AIS 8-40) and Health and Behavior Inventory (IZZ 24-120). RESULTS: The average age among respondents with OA has been 59.16 years of age $( \pm 15.87)$, duration of disease 5.5 years $( \pm 4.32)$. Experienced pain, both during movement $(\mathrm{r}=0.319, \mathrm{p}<0.001)$ and at rest $(\mathrm{r}=0.375, \mathrm{p}<0.001)$ correlated positively with physical disability (HAQ DI). Studies indicated a positive linear correlation between the age and physical disability $(\mathrm{rs}=0.200, \mathrm{p}=0.005)$. Acceptance of the disease (AIS) depends mostly on age $(\mathrm{r}=-0.325$, $\mathrm{p}<0.001)$, on pain in motion $(\mathrm{r}=-0.209, \mathrm{p}<0.001)$ and at rest $(\mathrm{r}=-0.218, \mathrm{p}<0.001)$ and on the disability levels $(\mathrm{r}=-0.353, \mathrm{p}<0.001)$. Analysis of the health-related behaviors (IZZ) indicates the average severity of declared behavior a statistically significant with physical disability (HAQ DI) $(p=0.029)$. CONCLUSIONS: With age and progressive levels of disability as well as with the severity of pain, the acceptance of illness is reduced significantly. The progressive levels of disability and younger age of the respondents motivate them to engage in health beneficial behavior. 
46

47

48

49

50

51

52

\section{INTRODUCTION}

Osteoarthritis - OA (morbus degenerativus articulorum), also known as a degenerative disease, is a group of overlapping disorders that despite their different etiologies lead to similar effects within the biological, morphological and clinical results. The disease affects ligaments, joint capsules, synovium, bursae, tendons, muscles, and it is often accompanied by the secondary damage to the nerves and veins (Bannell, Hunter \& Hinman 2012; Jordan et al. 2003). This applies in particular to the weight-bearing joints, for example knees, ankles, spine and upper limbs, less often hips.

The main physical problems of OA patients are: pain, contracture and distortion of joints as well as difficulty with moving and during performing basic tasks of self-care. The pain caused by the disease contributes to the feeling of anxiety, irritability, exhaustion, which in turn interfere with the everyday life functioning (Kool \& Geenen, 2012). The patients display behaviors resulting from the fear of losing physical mobility, such as depressive states, despondency, and reluctance to undertake any form of physical activity. Moreover, the progressive character of the disease causes problems within the social and professional spheres which lead to isolation, lack of acceptance of one's inability for professional work, restrictions in movement and limitations in performing basic daily living activities (Østerås et al., 2013; Kolanowski, 2010; Suri \& Walsh, 2012). Since for a large group of patients it is extremely difficult to adapt to the changes brought by the chronic, progressive disease it is important that they obtain professional help, support and health education. They should be prepared for a conscious participation in the treatment and self-care (Hill, 2006; Sierakowska et al., 2010a). Another key factor is laying the 
67 foundations for the proper health-related behaviors because that can reduce or even prevent the 68 progression of disability and physical dysfunctions.

69 Health behaviors that positively affect health are primarily a healthy diet, regular physical 70 activity and optimum amount of sleep per day, as well as self-control of the health state, 71 responsibility for one's own health and positive attitude (Banaszkiewicz et al., 2008).

72 In osteoarthritis, particular attention is paid to health behaviors that improve the function 73 of the musculoskeletal system. Patients have to take daily activity in the form of physical exercises tailored to their individual abilities, and daily walks to improve the overall condition. It is important to maintain a healthy diet in order to keep weight. Such actions help in reducing joint stress and pain (Sierakowska et al., 2010a). Given the adverse effect of non-steroidal antiinflammatory drugs, it is recommended to use them mainly topically on the painful joint. Physiotherapy can be also helpful in relieving pain and disability (Iwamoto et al., 2011). The patient's active participation in the treatment together with maintaining healthy lifestyle and behaviors that reduce the disability progression will improve his/her everyday life functioning and thus, the acceptance of disease will increase (Jordan et al., 2003; Hochberg et al., 2012; Bannell, Hunter \& Hinman 2012).

The authors aim to demonstrate the osteoarthritis not only from the biomedical perspective, but also as a psychological and existential problem of the patient who has been diagnosed with a chronic, progressive rheumatic disease. The applied research tools are based on the socialcognitive theories and refer to the holistic approach to health and disease. Therefore, the evaluation of patient's behavior focuses on health, physical complaints, methods of coping with the disease and treatment and consider cognitive, emotional and motivational aspects. This is 89 particularly important in the osteoarthritis, that leads to the reduced level of performance, high 
90 severity of health problems and dependence on the environment (Juczyński, 1999; Felton,

91 Revenson \& Hinrichsen, 1984a; Amir, 1987; Grohman, 1982). The mode of dealing with the

92 disease and initiating or discontinuing pro-health behaviors affects health related quality of life.

93 In planning treatment, care and targeted health education it is very helpful to know how the

94 patient is adapted to the disease and copes with it without experiencing negative emotions and 95 rejection (Juczyński, 1999; Hill, 2006; Sierakowska et al., 2010a).

96 THE AIMS OF THE STUDY: an attempt to evaluate the degree of acceptance of the

97 disease and pro-health behaviors, in relation to the major health problems in osteoarthritis 98 patients, such as pain and inability to independently perform activities of daily living; to

99 determine how selected demographic factors, such as age and sex, as well as the duration of 100 disease, affect the acceptance of osteoarthritis and taking pro-health behaviors and, in 101 consequence, the progression of pain and disability; an analysis of the actions undertaken by the 102 patients that could improve their well-being and everyday functioning (patients taking 103 analgesics, doing physical exercises on their own).

104 The researchers hypothesized that patients who engage in pro-health behaviors are able to 105 better cope with pain and progressive physical disability. The health beneficial behaviors should 106 improve the acceptance of the disease, which usually decreases with age and duration 107 osteoarthritis. An important task for health professionals is to motivate the patient to engage in 108 behaviors that are health beneficial. The authors have attempted to identify the factors affecting 109 the acceptance of disease and positive lifestyle, so that educational activities and support for OA 110 patients could be planned deliberately and accurately.

\section{MATERIALS AND METHODS}

\section{Participants and procedures}

113 
114 This cross-sectional correlational study included 198 patients diagnosed with osteoarthritis

115 of the knee, osteoarthritis of the hip and degenerative disease of the spine, within the program of

116 inpatient and outpatient care. The study was conducted at the Department of Rheumatology and

117 Internal Diseases, Medical University of Bialystok, Poland, during patients' hospitalization, and

118 at Rheumatology Outpatient Clinic in Augustow, during inspection visits to rheumatologists,

119 from April to November 2011. The patients were informed about the study and instructed how to

120 fill in the questionnaires independently and confidentially.

121 The inclusion criteria were: age $\geq 40$ years, diagnosis of OA according to ACR criteria

122 (1988) and informed consent to participate in the study. The criterion for exclusion from the

123 study was the existence of other, overlapping diseases of bones and joints, including

124 inflammatory joint diseases. Patients who met the criteria were qualified for the study according

125 to the order of their admission to the Department of Rheumatology or visit in Rheumatology

126 Outpatient Clinic.

\section{Ethics approval}

128 The study follows the Good Clinical Practice guidelines and it is in accordance with the

1291975 Helsinki Declaration revised in 2000 (concerning the ethical principles for the medical

130 community and forbidding releasing the name of the patient, initials or the hospital evidence

131 number) and with the ethical standards of the Institutional Committee on Human

132 Experimentation (statute from the Bioethics Committee of the Medical University in Bialystok,

133 Poland, no. RI-002/572/2011).

\section{Study instruments}

135 The method used was a diagnostic survey, using a measurement tools used in the

136 promotion of health and health psychology that are accessible to health professionals, such as:

137 Acceptance of Illness Scale (AIS 8-40) by Felton, Revenson \& Hinrichsen (1984) adapted by 
138 Juczyński (1999), and Health Behavior Inventory (IZZ 24-120) by Juczyński (1999).

139 Additionally there was applied Visual-Analog Scale Assessment of Pain (Pain VAS) during 140 movement and resting (0-10), and Health Assessment Questionnaire Disability Index (HAQ DI $1410-3)$

142 Acceptance of Illness Scale (AIS) has been used for studying patients. It contains 8 143 statements that describe the negative consequences of ill health, taking into account the 144 limitations imposed by the disease, lack of self-sufficiency, the sense of dependence on others 145 and low self-esteem. The scale is used to measure the degree of disease acceptance (Juczyński, 146 1999). To evaluate the level of the acceptance of disease, the results were interpreted within the 147 scale of $8-40$ points. The higher the score, the greater acceptance of disease, better adaptation 148 to the limitations imposed by the disease and lesser the sense of psychological discomfort.

149 Health Behavior Inventory (IZZ) is designed for studying healthy and ill adults. It 150 comprises 24 statements that describe the intensity of health-related behaviors. The scale allows 151 for the evaluation of the intensity of health-related behaviors in four areas (1-5): proper eating 152 habits (type of food intake e.g. vegetables, fruit, whole wheat bread) preventive behavior 153 (following doctor's recommendations, interest in knowledge about the disease), positive mental 154 attitude (avoiding strong emotions and stress) and healthy practices (sleep, recreation, physical 155 activity). IZZ is helpful in planning measures of prevention, behavior modification determining 156 the direction and monitoring of changes in health practices (Sierakowska et al., 2010a). For the 157 overall evaluation of health-related behaviors, the results are interpreted within the scale of 24158120 points. They can be converted into raw values standard ten (1-10), given the temporary 159 standards for men and women (1-4 standard ten scores low F 24-77, M 24-71; average 5-6 F 78160 91, M 72-86 7-10 92-120 high F, M 87 - 120) (Juczyński, 1999). 
162 slight degree of pain (low), 3.6 - 6.5 - an average pain (medium), 6.6 - 10 - a strong degree of

163 felt pain (strong) (Wiland, Madaj \& Szmyrka-Kaczmarek, 2008).

164 The HAQ-DI evaluates the ability to perform daily activities during the last week. The

165 questionnaire consists of 20 basic questions, divided into 8 sections, in which the patient has a

166 choice of 4 possible answers: without difficulty, with certain difficulty, with difficulty, unable to

167 perform, regarding the activities of everyday life functioning (dressing and washing, morning

168 getting up, eating, walking, personal hygiene, lifting, gripping and movement). The

169 questionnaire also includes additional questions regarding the assistive devices used to facilitate

170 the functioning and the activities that require help of other people. The total score ranges from 0

$171-3: 0-1-$ little degree dysfunctions in any field of daily life; $>1-2-$ serious limitations or

172 need for help in daily activities; > 2 - 3 - total inability to do daily activities without help (Bruce

173 \& Fries, 2003; Thorsen et al., 2001).

\section{DATA ANALYSIS}

175 All data were analyzed using PQStat v.1.4.2 software. We tested the null hypothesis of no

176 correlation between health behavior, acceptance of disease and patient pain problem and

177 disability. Pearson $\left(\mathrm{r}_{p}\right)$ and Spearman $\left(\mathrm{r}_{s}\right)$ correlation coefficient is reported together with $\mathrm{p}$ -

178 values, with $\mathrm{r}$ of $0.10,0.20$ and 0.50 representing small, medium and large effects respectively.

179 The effects of sex, age and disease duration were tested across all measures. Students't-test was

180 used to assess gender differences and One-Way ANOVA for differences across age groups and

181 disease duration. The level of significance $\alpha=0.05$.

\section{RESULTS}

183 General characteristics of subjects with OA 
185 OA was women $(55.6 \%)$. The mean age was $59.16( \pm 15.87)$. The average time of disease

186 duration was $5.5( \pm 4.32)$ years. More than half of respondents $(56 \%)$ had OA longer than 10

187 years. As it is shown in Table 1., the largest group of patients $(n=100,50.5 \%)$ declared primary

188 education/vocational training and lived in the city $(n=122,61.6 \%)$. The vast majority $(n=138$,

$18970.1 \%)$ of subjects were retired and married $(n=147,74.2 \%)$.

190 The majority of respondents $(n=117,59 \%)$ were taking analgesics during the periods of the

191 disease's worsening. The level of physical activity was not satisfactory. More than half of

192 respondents $(n=104,52.5 \%)$ declared that they did not practice any sport. A large percentage of 193 respondents $(\mathrm{n}=88,44.7 \%)$ did not use any form of rehabilitation.

194 Table 1. Patient characteristics and outcomes (mean (SD) except where stated otherwise)

\begin{tabular}{|l|c|}
\hline \multicolumn{1}{|c|}{ Variables studied (score range) } & Mean ( \pm SD) \\
\hline Age & $59.16( \pm 15.87)$ \\
\hline Disease duration years & $5.5( \pm 4.32)$ \\
\hline sex - number of women (\%) & $110(55.6)$ \\
\hline Educational background & $100(50.5)$ \\
\hline \multicolumn{2}{|c|}{ basic/ professional - number (\%) } \\
\hline \multicolumn{2}{|c|}{ secondary - number (\%) } \\
\hline \multicolumn{2}{|c|}{$61(30.8)$} \\
\hline Place of residence - number (\%) & $37(18.7)$ \\
\hline city - number (\%) & $122(61.6)$ \\
\hline & $76(38.4)$ \\
\hline
\end{tabular}


Occupational status

\begin{tabular}{|r|r|}
\hline retired - number (\%) & $138(70.1)$ \\
\hline working - number (\%) & $55(27.9)$ \\
\hline unemployed - - number (\%) & $5(2.5)$ \\
\hline
\end{tabular}

Family Status

\begin{tabular}{|l|c|}
\hline \multicolumn{1}{|c|}{ married / married - number (\%) } & $147(74.2)$ \\
\hline \multicolumn{1}{|c|}{ widow / widower - number (\%) } & $43(21.7)$ \\
\hline Pain-VAS (0-10) in motion - number (\%) & $8(4.0)$ \\
\hline Pain-VAS (0-10) at rest & $5.92( \pm 1.90)$ \\
\hline HAQ-DI (0-3) & $4.95( \pm 2.27)$ \\
\hline AIS (8-40) & $1.10( \pm 0.92)$ \\
\hline IZZ (24-120) & $25.75( \pm 8.47)$ \\
\hline
\end{tabular}

VAS - visual - analogue scale; HAQ DI - Health Assessment Questionnaire Disability Index; AIS - Acceptance of Illness Scale; IZZ - Health Behavior Inventory

\section{The analysis of pain perception during motion and rest (Pain VAS)}

The mean of pain during movement in the studied group of OA patients, as presented in Table 1., was $5.92( \pm 1.90)$, and the rest $4.95( \pm 2.27)$, which indicates the average level of pain. In detailed analysis of the data on the severity of pain during movement, it was shown that more than half of all patients $(n=100,50.5 \%)$ declared a strong degree of experienced pain, $29.8 \%$ of patients $(\mathrm{n}=59)$ declared pain while resting.

The statistical analysis showed a statistically significant relationship between the perception of pain during movement and taking analgesics. Patients who did not take analgesics 
206 rated their pain lower significantly more often - Pain VAS $3.94( \pm 1.81)(\mathrm{p}<0.001)$. Patients who

207 declared average level of pain during movement - Pain VAS $6.10( \pm 1.91)$, more frequently 208 admitted regular taking analgesics. As it is shown in Table 2., there is a statistically significant 209 relationship between the level of pain at rest and analgesics intake $(p<0.001)$. With the increase 210 of pain at rest the frequency of intake of analgesics has been intensified.

211 The answers on the character of pain in relation to the physical exercises at home

212 (physiotherapy) suggest that the level of pain experienced both during movement and at rest was

213 slightly reduced through performing physical exercises at home, although it was not statistically

214 significant (data in Table 2).

215

216 Table 2. The level of pain during movement and resting (Pain VAS) in comparison to the 217 variables in the group with osteoarthritis.

\begin{tabular}{|c|c|c|c|c|}
\hline \multirow[t]{2}{*}{ Variables studied } & \multicolumn{2}{|c|}{ Pain in motion (VAS 0-10) } & \multicolumn{2}{|c|}{ Pain at rest (VAS $0-10$ ) } \\
\hline & Mean $( \pm S D)$ & $\begin{array}{l}{ }^{1} \text { F-statistic } \\
\text { (p-value) }\end{array}$ & $\operatorname{Mean}( \pm \mathrm{SD})$ & $\begin{array}{c}{ }^{1} \text { F-statistic } \\
\text { (p-value }\end{array}$ \\
\hline \multicolumn{5}{|l|}{ Sex } \\
\hline $\mathrm{F}$ & $5.1( \pm 2.22)$ & \multirow[t]{2}{*}{$0.12(0.694)$} & $5.0( \pm 2.35)$ & \multirow[t]{2}{*}{$0.12(0.732)$} \\
\hline $\mathrm{M}$ & $4.79( \pm 2.14)$ & & $4.88( \pm 2.17)$ & \\
\hline \multicolumn{5}{|l|}{ Age, years } \\
\hline $40-60$ & $4.62( \pm 1.92)$ & \multirow[t]{3}{*}{$0.74(0.708)$} & $4.83( \pm 2.17)$ & \multirow[t]{3}{*}{$0.22(0.802)$} \\
\hline $61-76$ & $4.96( \pm 1.57)$ & & $5.08( \pm 2.36)$ & \\
\hline$\geq 77$ & $4.76( \pm 2.54)$ & & $4.94( \pm 2.38)$ & \\
\hline Disease duration, & & & & \\
\hline
\end{tabular}




\begin{tabular}{|c|c|c|c|c|}
\hline years & & & & \\
\hline $0-5$ & $5.72( \pm 2.05)$ & \multirow[t]{3}{*}{$0.62(0.539)$} & $4.37( \pm 2.30)$ & \multirow[t]{3}{*}{$2.37(0.096)$} \\
\hline $6-10$ & $5.78( \pm 1.71)$ & & $4.86( \pm 2.03)$ & \\
\hline$>10$ & $6.05( \pm 1.90)$ & & $5.22( \pm 2.31)$ & \\
\hline \multicolumn{5}{|l|}{$\begin{array}{l}\text { Intake of } \\
\text { analgesics }\end{array}$} \\
\hline $\begin{array}{r}\text { during worsening of } \\
\text { symptoms }\end{array}$ & $6.10( \pm 1.75)$ & \multirow[t]{3}{*}{$\begin{array}{c}11.01 \\
(<\mathbf{0 . 0 0 1 )}\end{array}$} & $5.10( \pm 2.20)$ & \multirow[t]{3}{*}{$8.49(<\mathbf{0 . 0 0 1})$} \\
\hline systematically & $6.10( \pm 1.91)$ & & $5.21( \pm 2.25)$ & \\
\hline not taking & $3.94( \pm 1.81)$ & & $2.85( \pm 1.88)$ & \\
\hline \multicolumn{5}{|l|}{ Physical exercises } \\
\hline $\begin{array}{l}\text { doesn't perform } \\
\text { physical exercises }\end{array}$ & $5.87( \pm 2.08)$ & \multirow[t]{4}{*}{$0.84(0.471)$} & $4.89( \pm 2.33)$ & \multirow[t]{4}{*}{$1.19(0.313)$} \\
\hline $\begin{array}{r}\text { several times a } \\
\text { month }\end{array}$ & $6.42( \pm 1.60)$ & & $5.67( \pm 2.07)$ & \\
\hline 2-3 times a week & $5.82( \pm 1.64)$ & & $4.76( \pm 1.99)$ & \\
\hline daily & $5.69( \pm 1.78)$ & & $4.66( \pm 2.58)$ & \\
\hline
\end{tabular}

221 been used.. In the study group, as it is indicated in Table 1., the average HAQ DI score was at $2221.10( \pm 0.92)$. 
224 ( \pm 0.64$)$. The statistical analysis showed that there is a statistically significant relationship

225 between the level of inability in performing daily activities and $\operatorname{sex}(\mathrm{p}=0.012)$ (data in Table 3$)$.

226 The average level of disability in the age group $\geq 77$ years was $1.22( \pm 0.72)$ (it was the 227 highest value in all groups) $(\mathrm{p}=0.028)$. The study has shown that more than half of the patients $228(62.4 \%)$ aged $\geq 77$ years, declared major restrictions or the need for help in daily living activities 229 (HAQ DI>1-2). The study indicated a positive linear correlation, showed in Table 3., between 230 the age and physical disability $\left(r_{s}=0.200, \mathrm{p}=0.005\right)$.

231 The evaluation of skills in everyday life, as presented in Table 3., has been positive in 232 patients who declared that they were not taking any analgesics (HAQ DI $0.59 \pm 0.43$ ). 233 Respondents who regularly took analgesics obtained the highest level of disability (HAQ DI 1.31 $234 \pm 0.73$ ). There has been observed a statistically significant relationship between the level of 235 disability in the performance of activities of daily life and the intake of analgesics $(\mathrm{p}=0.012)$.

236 The study indicated a statistically significant correlation between the level of pain during 237 movement and physical disability (HAQ DI) $(\mathrm{p}<0.001)$, as presented in Table 3. Patients who 238 declared strong level of pain, declared also serious limitations on performing daily life activities 239 (HAQ DI 1.25 \pm 0.68$)$. There was a positive linear correlation $\left(r_{s}=0.319, \mathrm{p}<0.001\right)$ between the 240 Pain VAS and HAQ DI. The average value for the level of disability among patients who 241 declared a strong level of pain at rest was $1.47( \pm 0.63)$. It has been observed that along with 242 mobility improvement, the level of pain decreased $\left(r_{s}=0.382, \mathrm{p}<0.001\right)$ (Table 3$)$.

243 Table 3. The level of physical disability (HAQ DI) in comparison to the variables in the group 244 with osteoarthritis. 


\begin{tabular}{|c|c|c|c|}
\hline & Mean $( \pm$ SD) & $\begin{array}{l}{ }^{1} \text { F-statistic } \\
\text { (p-value) }\end{array}$ & ${ }^{2} \mathrm{r}_{\mathrm{s}} \mathrm{p}$-value $)$ \\
\hline \multicolumn{4}{|l|}{ Sex } \\
\hline $\mathrm{F}$ & $1.25( \pm 1.07)$ & \multirow[t]{2}{*}{$6.38(\mathbf{0 . 0 1 2})$} & \\
\hline $\mathrm{M}$ & $0.92( \pm 0.64)$ & & \\
\hline \multicolumn{4}{|l|}{ Age, years } \\
\hline $40-60$ & $0.98( \pm 1.17)$ & \multirow[t]{3}{*}{$1.37(\mathbf{0 . 0 2 8})$} & \multirow[t]{3}{*}{$0.200(\mathbf{0 . 0 0 5})$} \\
\hline $61-76$ & $1.18( \pm 0.64)$ & & \\
\hline$\geq 77$ & $1.22( \pm 0.72)$ & & \\
\hline \multicolumn{4}{|l|}{ Disease duration, years } \\
\hline $0-5$ & $0.93( \pm 1.47)$ & \multirow[t]{3}{*}{$1.56(0.211)$} & \\
\hline $6-10$ & $1.03( \pm 0.67)$ & & \\
\hline$>10$ & $1.20( \pm 0.66)$ & & \\
\hline \multicolumn{4}{|l|}{ Intake of analgesics } \\
\hline $\begin{array}{r}\text { during worsening of } \\
\text { symptoms }\end{array}$ & $1.06( \pm 1.03)$ & \multirow[t]{3}{*}{$4.49(\mathbf{0 . 0 1 2})$} & \\
\hline systematically & $1.31( \pm 0.73)$ & & \\
\hline not taking & $0.59( \pm 0.43)$ & & \\
\hline \multicolumn{4}{|l|}{ Physical exercises } \\
\hline $\begin{array}{r}\text { doesn't perform physical } \\
\text { exercises }\end{array}$ & $1.17( \pm 1.11)$ & \multirow[t]{2}{*}{$0.80(0.496)$} & \\
\hline several times a month & $1.16( \pm 0.60)$ & & \\
\hline
\end{tabular}




\begin{tabular}{|c|c|c|c|}
\hline 2-3 times a week & $1.03( \pm 0.62)$ & & \\
\hline daily & $0.88( \pm 0.71)$ & & \\
\hline \multicolumn{4}{|l|}{$\begin{array}{l}\text { Pain VAS in motion }(0- \\
10)\end{array}$} \\
\hline low & $0.81( \pm 1.90)$ & \multirow{3}{*}{$\begin{array}{l}18.50 \\
\quad(<\mathbf{0 . 0 0} \\
\text { 1) }\end{array}$} & \multirow{3}{*}{$\begin{array}{c}0.319 \\
(<\mathbf{0 . 0 0 1})\end{array}$} \\
\hline medium & $1.01( \pm 0.64)$ & & \\
\hline strong & $1.25( \pm 0.68)$ & & \\
\hline \multicolumn{4}{|l|}{ Pain VAS at rest $(0-10)$} \\
\hline low & $0.92( \pm 1.28)$ & \multirow{3}{*}{$\begin{array}{c}18.28 \\
(<\mathbf{0 . 0 0 1})\end{array}$} & \multirow[t]{3}{*}{$0.382(<\mathbf{0 . 0 0 1})$} \\
\hline medium & $0.97( \pm 0.60)$ & & \\
\hline strong & $1.47( \pm 0.63)$ & & \\
\hline
\end{tabular}

${ }^{1}$ the univariate ANOVA for independent groups, ${ }^{1}$ F-statistic; ${ }^{2} r_{S}$ Spearman correlation; HAQ DI - Health Assessment Questionnaire Disability Index

\section{Correlates of disease acceptance (AIS)}

The average value level of the acceptance of disease in the study group, as presented in

251 among patients with diagnosed OA.

With age the level of acceptance of the disease significantly worsened. The results of 253 statistical analysis showed that there was a statistically significant correlation between the level

254 of acceptance of the disease and the age $\left(r_{s}=-0.325, \mathrm{p}<0.001\right)$. 
In the statistical analysis of the variable of disease duration and the level of acceptance of

256 the disease, it was observed, as shown in Table 4., that along with the duration of OA the level of

257 acceptance of the disease significantly decreases ( $>10$ years - AIS $23.71( \pm 7.79)$. The analysis

258 indicated a statistically significant relationship between the variables $(\mathrm{p}<0.001)$.

259 The patients who declared that they do not take any analgesics assessed the acceptance of 260 the disease on a good level - AIS 30.64 ( \pm 9.30$)$ and those who take analgesics systematically

261 pointed to the average level of the disease acceptance - AIS $24.35( \pm 9.10)(\mathrm{p}=0.023)$ (data in 262 Table 4).

263 As it is shown in Table 4., it has been observed a negative correlation $\left(r_{p}=-0.209, \mathrm{p}<0.001\right)$

264 between the level of the disease acceptance and the degree of pain during movement. Along with 265 the seriousness of pain the capacity to accept the disease decreased. A relation between the level 266 of acceptance of disease and the degree of pain at rest $\left(r_{p}=-0.218, \mathrm{p}<0.001\right)$ has been also 267 demonstrated.

268 The results also indicate a negative linear correlation between the acceptance of illness and 269 the level of disability (HAQ DI) $\left(r_{p}=-0.353, \mathrm{p}<0.001\right)$. This proves that the higher the acceptance 270 of OA, the lower the level of physical disability.

271 The average value for the level of acceptance of disease among those declaring a slight 272 dysfunction in every area of everyday life (HAQ 0-1) was $28.75( \pm 8.53)$, and among patients 273 reporting a total inability in performing activities of daily living (HAQ $>2-3)-21.06( \pm 6.02)$ $274(\mathrm{p}<0.001)$ (data in Table 4).

\section{5}

276 Table 4. Correlates of disease acceptance and health behaviors in the group with osteoarthritis.

\begin{tabular}{|l|l|l|}
\hline Variables & AIS (8-24) & IZZ (24-120) \\
\hline
\end{tabular}




\begin{tabular}{|c|c|c|c|c|c|}
\hline studied & Mean $( \pm S D)$ & $\begin{array}{c}{ }^{1} \mathrm{~F}- \\
\text { statistic/ } \\
\text { p-value }\end{array}$ & $\begin{array}{c}{ }^{2} r_{s /}{ }^{3} r_{p} \\
(\mathrm{p}- \\
\text { value) }\end{array}$ & Mean $( \pm S D)$ & $\begin{array}{c}{ }^{1} \text { F-statistic/ } \\
\text { p-value }\end{array}$ \\
\hline \multicolumn{6}{|l|}{ Sex } \\
\hline $\mathrm{F}$ & $\begin{array}{c}30.23 \\
( \pm 8.45)\end{array}$ & \multirow[t]{2}{*}{$\begin{array}{c}2.51 \\
(0.115)\end{array}$} & & $\begin{array}{c}92.51 \\
( \pm 14.02)\end{array}$ & \multirow[t]{2}{*}{$\begin{array}{c}4.67 \\
(<\mathbf{0 . 0 0 1 )}\end{array}$} \\
\hline $\mathrm{M}$ & $\begin{array}{c}28.22 \\
( \pm 7.54)\end{array}$ & & & $\begin{array}{c}83.23 \\
( \pm 15.44)\end{array}$ & \\
\hline \multicolumn{6}{|l|}{ Age, years } \\
\hline $40-60$ & $\begin{array}{c}28.47 \\
( \pm 7.84)\end{array}$ & $\begin{array}{c}9.46 \\
(<\mathbf{0 . 0 0 1 )}\end{array}$ & $\begin{array}{l}2-0.325 \\
(<0.001\end{array}$ & $\begin{array}{c}87.25 \\
( \pm 16.85)\end{array}$ & $3.47(\mathbf{0 . 0 3 3})$ \\
\hline $61-76$ & $\begin{array}{c}24.42 \\
( \pm 8.27)\end{array}$ & \multirow{2}{*}{$(<0.001)$} & \multirow{2}{*}{$\begin{array}{c}(<0.001 \\
)\end{array}$} & $\begin{array}{c}91.84 \\
( \pm 12.75)\end{array}$ & \\
\hline$\geq 77$ & $\begin{array}{c}22.23 \\
( \pm 8.45)\end{array}$ & & & $\begin{array}{c}84.43 \\
( \pm 15.34)\end{array}$ & \\
\hline \multicolumn{6}{|l|}{$\begin{array}{l}\text { Disease } \\
\text { duration, } \\
\text { years }\end{array}$} \\
\hline $0-5$ & $30.31( \pm 8.54)$ & $\begin{array}{c}11.11 \\
(<\mathbf{0 . 0 0 1})\end{array}$ & & $\begin{array}{c}87.46 \\
( \pm 15.47)\end{array}$ & $1.06(0.349)$ \\
\hline $6-10$ & $26.05( \pm 8.25)$ & & & $\begin{array}{c}85.82 \\
( \pm 17.43)\end{array}$ & \\
\hline
\end{tabular}




\begin{tabular}{|c|c|c|c|c|}
\hline$>10$ & $23.71( \pm 7.79)$ & & $\begin{array}{c}89.46 \\
( \pm 14.46)\end{array}$ & \\
\hline \multicolumn{5}{|l|}{$\begin{array}{l}\text { Intake of } \\
\text { analgesics }\end{array}$} \\
\hline $\begin{array}{r}\text { during } \\
\text { worsening of } \\
\text { symptoms }\end{array}$ & $\begin{array}{r}25.80 \\
( \pm 7.76)\end{array}$ & $\begin{array}{c}3.81 \\
(\mathbf{0 . 0 2 3})\end{array}$ & $\begin{array}{c}87.43 \\
( \pm 15.20)\end{array}$ & $1.56(0.213)$ \\
\hline systematically & $\begin{array}{r}24.35 \\
( \pm 9.10)\end{array}$ & & $\begin{array}{c}91.01 \\
( \pm 15.46)\end{array}$ & \\
\hline not taking & $\begin{array}{c}30.64 \\
( \pm 9.30)\end{array}$ & & $\begin{array}{c}85.11 \\
( \pm 15.33)\end{array}$ & \\
\hline \multicolumn{5}{|l|}{$\begin{array}{l}\text { Doing } \\
\text { physical } \\
\text { exercises }\end{array}$} \\
\hline $\begin{array}{l}\text { doesn't } \\
\text { perform } \\
\text { physical } \\
\text { exercises }\end{array}$ & $\begin{array}{c}25.26 \\
( \pm 8.83)\end{array}$ & $\begin{array}{c}0.38 \\
(0.765)\end{array}$ & $\begin{array}{c}82.67 \\
( \pm 15.91)\end{array}$ & $\begin{array}{c}13.31 \\
(<\mathbf{0 . 0 0 1})\end{array}$ \\
\hline $\begin{array}{r}\text { several times a } \\
\text { month }\end{array}$ & $\begin{array}{c}26.92 \\
( \pm 8.22)\end{array}$ & & $\begin{array}{c}90.85 \\
( \pm 10.67)\end{array}$ & \\
\hline $\begin{array}{r}2-3 \text { times a } \\
\text { week }\end{array}$ & $\begin{array}{r}26.38 \\
( \pm 8.03)\end{array}$ & & $\begin{array}{c}97.64 \\
( \pm 10.51)\end{array}$ & \\
\hline
\end{tabular}




\begin{tabular}{|c|c|c|c|c|c|}
\hline daily & $\begin{array}{r}25.48 \\
( \pm 8.17)\end{array}$ & & & $\begin{array}{c}94.51 \\
( \pm 14.02)\end{array}$ & \\
\hline \multicolumn{6}{|l|}{$\begin{array}{l}\text { Pain VAS in } \\
\text { motion }(0-10)\end{array}$} \\
\hline low & $\begin{array}{r}29.82 \\
( \pm 8.70)\end{array}$ & \multirow[t]{3}{*}{$\begin{array}{c}3.38 \\
(0.036)\end{array}$} & \multirow{3}{*}{$\begin{array}{c}{ }^{3}-0.209 \\
(<\mathbf{0 . 0 0 1} \\
)\end{array}$} & $\begin{array}{c}87.83 \\
( \pm 15.50)\end{array}$ & \multirow[t]{3}{*}{$0.28(0.753)$} \\
\hline medium & $\begin{array}{r}25.80 \\
( \pm 8.38)\end{array}$ & & & $\begin{array}{c}89.46 \\
( \pm 15.07)\end{array}$ & \\
\hline strong & $\begin{array}{r}24.68 \\
( \pm 8.23)\end{array}$ & & & $\begin{array}{c}87.52 \\
( \pm 15.96)\end{array}$ & \\
\hline \multicolumn{6}{|l|}{$\begin{array}{l}\text { Pain VAS at } \\
\text { rest }(0-10)\end{array}$} \\
\hline low & $\begin{array}{r}27.18 \\
( \pm 8.66)\end{array}$ & \multirow[t]{3}{*}{$\begin{array}{c}4.14 \\
(\mathbf{0 . 0 1 7})\end{array}$} & \multirow{3}{*}{$\begin{array}{c}{ }^{3}-0.218 \\
(<\mathbf{0 . 0 0 1} \\
)\end{array}$} & $\begin{array}{c}86.60 \\
( \pm 15.26)\end{array}$ & \multirow[t]{3}{*}{$0.73(0.482)$} \\
\hline medium & $\begin{array}{r}27.04 \\
( \pm 7.93)\end{array}$ & & & $\begin{array}{r}88.86 \\
( \pm 15.51)\end{array}$ & \\
\hline strong & $\begin{array}{r}22.55 \\
( \pm 8.10)\end{array}$ & & & $\begin{array}{c}89.81 \\
( \pm 15.30)\end{array}$ & \\
\hline \multicolumn{6}{|l|}{ HAQ DI (0-3) } \\
\hline $0-1$ & $\begin{array}{r}28.75 \\
( \pm 8.53)\end{array}$ & $\begin{array}{c}11.53 \\
(<\mathbf{0 . 0 0 1})\end{array}$ & $\begin{array}{l}3_{-}^{3} 0,353 \\
\text { (<0.001 }\end{array}$ & $\begin{array}{c}87.81 \\
( \pm 15.26)\end{array}$ & $3.59(\mathbf{0 . 0 2 9})$ \\
\hline$>1-2$ & 22.20 & & ) & 87.12 & \\
\hline
\end{tabular}




\begin{tabular}{|c|c|c|c|c|c|}
\hline & $( \pm 6.93)$ & & & $( \pm 15.33)$ & \\
\cline { 1 - 2 } & 21.06 & & & 98.06 & \\
& $( \pm 6.02)$ & & & $( \pm 13.30)$ & \\
\hline
\end{tabular}

277

278

279

280

281

282

283

284

285

286

287

288

289

290

291

292

293

294

295

296

297

298

${ }^{1}$ the univariate ANOVA for independent groups; ${ }^{2} r_{S}$ Spearman correlation; ${ }^{3} r_{p}$, Pearson's correlation coefficient, where $0.10,0.20$ and 0.50 represent small, medium and large effects respectively; HAQ DI - Health Assessment Questionnaire Disability Index; AIS - Acceptance of Illness Scale; IZZ - Health Behavior Inventory

\section{Correlates of the inventory of health-related behaviors (IZZ)}

In the general analysis of inventory of health-related behaviors it has been observed an average intensity of declared behavior - IZZ $88.39( \pm 15.34)$ (Table 1).

As it is shown in Table 4., health behaviors in the group of women was $92.51( \pm 14.02)$, while in men $83.23( \pm 15.44)(\mathrm{p}<0.001)$. The detailed analysis showed that $61.8 \%$ of women and $42 \%$ of men reported a high occurrence of health-related behaviors.

Given the age factor, mean value of inventory of health behaviors in the group $\geq 77$ years was the lowest, compared to other age groups, and was $84.43( \pm 15.34)$. The analysis showed a statistically significant relationship between the declared health behavior and the age of the patients $(\mathrm{p}=0.033)$ (Table 4).

Analysis of health-related behaviors in relation to the applied physiotherapy at home, showed that patients performing physical exercises every day, declared a high intensity of the declared pro-health behaviors - IZZ $94.51( \pm 14.02)$, while those who did not practice any sport pointed to medium/average occurrence of pro-health behaviors - IZZ $82.67( \pm 15.91)(\mathrm{p}<0.001)$ (data in Table 4).

In seeking the significant relationship between health behaviors (IZZ), and the level of disability (HAQ DI), presented in Table 4., there has been found that the patients declaring 
299 dysfunction of slight intensity in every area of everyday life (HAQ DI 0-1) pointed to the

300 average severity of health behaviors $-87.81( \pm 15.26)$, while patients requiring total assistance in

301 performing daily life activities (HAQ DI> 2-3) declared a high intensity of health-related

302 behaviors $-98.06( \pm 13.30)(\mathrm{p}=0.029)$. The study showed no statistical significant linear

303 correlation between health-related behaviors and the studied variables.

304 Separate calculation of the four categories of health behaviors (1-5), indicates that the

305 average value for healthy eating habits was to $3.70( \pm 0.55)$, preventive behaviors- $4.13( \pm 0.60)$,

306 positive mental attitude $-3.87( \pm 0.60)$, and health practices $-3.76( \pm 0.60)$. The study has shown

307 that the patients received the highest score in the category of preventive behaviors, regarding

308 treatment compliance and obtaining information about health and disease, and the lowest in the

309 category of proper eating habits (type of food they eat).

310 In the analysis of the relationship between the level of acceptance of the disease (AIS) and

311 undertaking health-related behaviors (IZZ), there was no statistically significant dependence

312 between two analyzed variables.

313 DISCUSSION

314 Osteoarthritis is the most common rheumatic disease that leads to progressive disability,

315 and influences all spheres of the patient's life: the physical, psychological, social and

316 occupational (Bannell, Hunter \& Hinman 2012; Jordan et al. 2003).

317 The progressive nature of osteoarthritis undoubtedly affects the level of disease acceptance

318 and development of individual pro-health behaviors. It should be remembered that health

319 beneficial activities promote better health, well-being and might affect further development of

320 the disease and disability (Sierakowska et al., 2010a). An essential psychological factor that 
321 helps in coming to terms with the level of progressive disability and escalation of pain is the 322 acceptance of disease.

323 Generally in our study, there has been observed that the acceptance of osteoarthritis is

324 affected mainly by such factors as age, pain, disability, and disease duration. Taking pro-health

325 behaviors depended greatly on the level of disability, age and sex. One of the manifestations of

326 pro-health behaviors was performing physical exercises from two to three times a week.

327 Considering the analysis of the main health problems, the study has shown a positive correlation

328 between the perception of pain and the level of physical disability. The intensification of both

329 variables impacted the intake of analgesics. The evaluation of the level of disability depended

330 also on age and sex.

331 The dominant problem, from the patient's point of view, is pain experienced during

332 performing physical activities, and to a lesser extent, during resting. The pain of the disease

333 contributes to the feeling of anxiety, irritability, exhaustion, which in turn causes disturbances in

334 the everyday life functioning (Kool \& Geenen, 2012; Chen et al, 2011).

335 Study result indicate a negative linear correlation between the level of disease acceptance,

336 the, pain felt during movement and at rest and the level of disability. Severe pain and progressive

337 difficulty in daily functioning significantly influence the level of acceptance of the disease.

338 In terms of disability in OA patients Cuperus et al. (2015) there has been showed that the

339 progressive nature of the disease negatively impacts patients' functioning in everyday activities.

340 As a result, in most cases, they need the help of others on performing basic tasks, e.g. walking,

341 eating, personal hygiene, or shopping. In our study it has been observed that the main physical

342 activities which require the help of other people are reaching, grasping, opening, receiving and

343 handling things. It has been observed that there is a statistically significant correlation between 
344 the perception of pain during movement and at rest, and the level of disability during the

345 performance of daily life activities of (HAQ DI).

346 In the reviewed literature there is a significant correlation between the level of pain and

347 disability in OA patients. Pain created various limitations to varying degrees, not only in the

348 performance of professional duties, but also in daily activities and in the pursuing of personal

349 interests (Jadhav et al., 2001). Reis et al. (2014) indicate that in women diagnosed with OA,

350 there is a significant relationship between the pain and the level of disability during performing

351 basic daily life activities, which is similar to our study result.

352 Taking the age factor into account it can be noticed that the younger group had a higher

353 degree of disease acceptance than the group of elderly people. It has been also observed that

354 along with the disease duration the acceptance of health situation deteriorated and the patients

355 presented worse adaptation and a greater sense of psychological discomfort. The study of

356 Creedon \& Weathers (2011) shows that patients with diagnosed OA are older and that they are

357 able to more easily accept their health and adopt a positive attitude towards the disease. The

358 researchers emphasize, however, that the relationship between the pain and the disease

359 acceptance is a normal part of the aging process and it can significantly limit the patient's ability

360 to independently perform activities of daily life. Nevertheless, Baird (2003) argues that women

361 have greater difficulties in accepting their illness, disability and pain. In this study there are no

362 significant differences concerning sex in analyzing variable acceptance of OA. There has been

363 also observed that there is a relationship between the disability during the performance of daily

364 life activities, sex and age. Women assessed their self-care ability worse (HAQ DI) than men.

365 The review of the literature also pointed out the relationship between the level of physical ability 
366 and patients' sex (Wilmańska \& Gułaj, 2006) and age. Studies by Kool and Geenen (2012) on

367 OA patients, showed that $>56 \%$ of patients older that, 77 years needed a constant regular care.

368 In our study patients who experienced pain of a fairly large severity and who have

369 difficulty in performing daily life activities more often take analgesics and non-steroidal non-

370 inflammatory drugs. According to the recommendations for the therapeutic approach to OA on

371 the basis of the American College of Rheumatology (ACR), European League Against

372 Rheumatism (EULAR) and Osteoarthritis Research Society International (OARSI)

373 recommendations, in case of treatment ineffectiveness, the recommended pharmacotherapy of

374 pain is based on non-steroidal anti-inflammatory drugs such as paracetamol, at the lowest

375 effective dose and for as short period of time as possible. The optimal therapeutic management

376 of OA requires the combined use of non-pharmacological and pharmacological treatment. It

377 should be noticed that the literature review reveals that patients with osteoarthritis tend to

378 overuse the aforementioned drugs (Jordan et al., 2003; Hochberg et al., 2012; Zhang et al.,

379 2008). The patients with osteoarthritis overtake the non-steroidal anti-inflammatory drugs

380 wanting to stimulate fast therapeutic effect, which only adds to the drugs' side effects. According

381 to the authors, patients hold the false belief about their positive effects on the course of the

382 disease, not taking into account the adverse drug reactions (Jordan et al., 2003; Zhang et al., 383 2008).

384 In the prophylaxis and during treatment of the osteoarthritis it is also important to 385 implement behaviors that are beneficial for health. Literature review shows that little physical 386 activity and lack of motivation for regular exercising is a substantial problem in patients with 387 OA., It is important to know what are the recommended types of physical exercises for the 388 individual patient, how to effectively perform them, and how to combat the pain. It is advised 
389 that patients understand the benefits of physiotherapy, because many of them do not follow the

390 physical treatment recommendations out of fear of exacerbating the pain (Hill, 2006;

391 Sierakowska et al., 2010a; Sierakowska et al., 2010b). In our study, almost half of the patients

392 did not use any form of rehabilitation.

393 There has been observed a statistically significant relationship between the declared health

394 behavior and the age of patients. Patients aged 61-76 years compared with older and younger

395 patients, pointed to the higher occurrence of pro-health behaviors. However according to the

396 study of Gignac et al. (2013) middle-aged people are more satisfied with coping with the disease

397 in comparison with the subjects who were healthy and older. According to the authors of this

398 study, the results indicate that with age the physical ability deteriorates, which motivates patients

399 to engage in pro-health behaviors. This is confirmed by the fact that patients who declared

400 dysfunction of slight intensity in every area of everyday life pointed to medium/average

401 occurrence of healthy behaviors, while patients who required total assistance in performing daily

402 living activities declared a high occurrence of pro-health behaviors. The subjects with a higher

403 level of pro-health behavior were involved in regular physical exercises that improved their

404 physical ability and well-being. A study by Hawker et al. (2011) also showed the impact of pro-

405 health behaviors on the progression of disability and everyday life functioning.

406 Detailed analysis of the categories of health behavior showed that the study group obtained

407 the lowest average score in healthy eating habits, and the higher score in prevention.

408 Nevertheless, according to Juczyński women during menopause declared the overall behavior

409 somewhat lower, especially for health practices, and the highest score, as in our study, was in

410 prophylactics. Pro-health behavior of adult men were lower than women (Juczyński, 1999).

411 Standards for osteoarthritis treatment emphasize the importance of self-care, proper lifestyle and 
412 rehabilitation. A patient who is able to self-manage his/her own life, accepts the disease and

413 becomes independent, adapts to changing conditions and learns to live and work, despite the

414 existing restrictions at home, at work and in the social environment (Hill, 2006; Sierakowska et 415 al., 2010a; Sierakowska et al., 2014).

416 It is worth noting that the social situation of the elderly, i.e. the possibility of obtaining

417 emotional support from the immediate environment, significantly affects the level of acceptance

418 of the disease and disability. The task of the therapeutic team is not only administering effective

419 treatment, but also providing support and advice on how to handle problems of everyday life, as 420 well as stress and limitations caused by the disease (Long et al., 2002; Tak \& Laffrey, 2003;

421 Sierakowska et al., 2010b).

\section{Paper limitations}

The study of patients with osteoarthritis has its limitations due to the applied research tool questionnaire that is based on the patients' assessment of their own health; thus independent verification of data is impossible. The correlational design prevents causal interference. Another Poland (Podlasie voivodeship), therefore, the results do not refer to the entire population of Polish patients diagnosed with OA.

\section{CONCLUSIONS}

1. Although women declare slightly higher difficulties in everyday activities than men, they exhibit more positive health conducive behavior.

2. With age and progressive levels of disability as well as with the severity of pain, the acceptance of disease is reduced significantly. 
434

435

436

437

438

439

440

441

442

443

444

446

447

449

450

451

452

453

454

455

456

3. The progressive levels of disability and younger age of the patients motivate them to engage in health beneficial behaviors. The subjects present positive pro-health behavior and undertake regular physical exercises.

4. High intensity of pain and progressive disability impact patients' decisions to follow treatment recommendations regarding analgesics.

The study has shown the need for taking measures aimed at stimulating patients' motivation to improve their physical ability and health education. Particularly the elderly people should be more engaged in daily physical activity. The challenge for health professionals is to fight off pain caused by arthritis, primarily through the use of non-pharmacological methods of pain management, as well as a greater access to the various forms of rehabilitation. In planning the health education, the attention should be paid also to the pro-health dietary advice.

Further work is planned to develop and implement an education program to promote healthy, active lifestyles and rehabilitation for patients with osteoarthritis, especially for patients with long disease duration and the elderly, with the level of disability HAQ DI $>1$ and Pain VAS $>5 \mathrm{~cm}$. It will be also important to motivate men to participate in organized educational activities as well as in rehabilitation. Three and six months after the program ending it is planned to evaluate the effectiveness of pro-health behaviors undertaken independently by the patients and their impact on the evaluation of pain, disability and the disease acceptance, while using standardized measurement tools.

\section{REFERENCES}

Baird CL. 2003. Holding on self-caring with osteoarthritis. Journal of Gerontological Nursing 29: 32-39. 
457 Banaszkiewicz M, Andruszkiewicz R. (ed.) 2008. Promocja zdrowia (Health promotion). $458 \quad$ Wydawnictwo Czelej. Lublin.

459 Bannell KL, Hunter DJ, Hinman RS. 2012. Management of osteoarthritis of the knee. BMJ 460 345: e4934 DOI: 10.1136/bmj.e4934.

461 Bruce B, Fries JF. 2003. The Stanford Health Assessment Questionnaire: Dimensions and 462 Practical Applications. Health and Quality of Life Outcomes 1:20 DOI: 10.1186/1477-7525$463 \quad 1-20$.

464 Chen Q, Hayman LL, Shmerling RH, Bean JF, Leveille SG. 2011. Characteristics of chronic 465 pain associated with sleep difficulty in older adults: the maintenance of balance, independent 466 living, intellect, and zest in the elderly (MOBILIZE) Boston study. American Geriatrics Society 59: 1386 - 1392 DOI: 10.1111/j.1532-5415.2011.03544.

Creedon R, Weathers E. 2011. The impact of nurse prescribing on patients with osteoarthritis. British Journal of Community Nursing 16: 393- 398. 2015. The clinical burden of generalized osteoarthritis represented by self-reported healthrelated quality of life and activity limitations: a cross-sectional study. Rheumatology International 35 (5): 871-877 DOI:10.1007/s00296-014-3149-1.

Felton BJ, Revenson TA, Hinrichsen GA. 1984. Stress and coping in the explanation of psychological adjustment among chronically ill adults. Social Science \& Medicine 18: 889898.

Iwamoto J, Sato Y, Takeda T, Hideo Matsumoto H. 2011. Effectiveness of exercise for osteoarthritis of the knee: A review of the literaturę. World Journal of Orthopedics. 2: 37-42. 
480 Gignac MA, Backman CL, Davis AM, Lacaille D, Cao X, Badley EM. 2013. Social role

481 participation and the life course in healthy adults and individuals with osteoarthritis: are we 482 overlooking the impact on the middle-aged? Social Science \& Medicine 81: 87-93 DOI: $483 \quad$ 10.1016/j.socscimed.2012.12.013.

484 Grohman D. 1982. Labels, systems and motives: Some perspectives for future research and 485 program. Health Education Quarterly 9, 167-173.

486 Hawker GA, Gignac MA, Badley E, Davis AM, French MR, Li Y, Perruccio AV, Power 487 JD, Sale J, Lou W. 2011. A longitudinal study to explain the pain-depression link in older adults with osteoarthritis. Arthritis Care \& Research 63: 1382-1390 DOI: 10.1002/acr.20298.

Hill J. 2006. Patient education. In: Hill J, ed. Rheumatology nursing. A creative approach. John Wiley\&Sons, Ltd, 436-458.

Hochberg MC, Altman RD, April KT, Benkhalti M, Guyatt G, McGowan J, Towheed T, Welch V, Wells G, Tugwell P. 2012. American College of Rheumatology 2012 recommendations for the use of nonpharmacologic and pharmacologic therapies in osteoarthritis of the hand, hip, and knee. Arthritis Care \& Research 64: 465-474.

Jadhav MP, Mutke AP, Sonawane SP, Sonawane SD, Patil BD, Naik NB, Sonawale AS. 2001. Prospective observational study to assess quality of life and prescription pattern in osteoarthritis patients at tertiary health centre in Mumbai. Indian Journal of Medical Sciences 65: 58-63 DOI: 10.4103/0019-5359.103963. 

the management of knee osteoarthritis: Report to a task force of standing committee for international clinical studies including therapeutic trials (ESCISIT). Annals of the Rheumatic Diseases 62: 1145-1155 DOI:10.1136/ard.2003.011742.

Juczyński Z. 1999. Measurement tools in the health psychology. The Review of Psychology 42: 43-56. (Polish)

Kolanowski AM. 2010. Best evidence of psychosocially focused nonpharmacologic therapies for symptom management in older adults with osteoarthritis. Pain Management Nursing 11: $234-244$.

Kool MB, Geenen R. 2012. Loneliness in patients with rheumatic diseases: the significance of invalidation and lack of social support. Journal of Psychology 146: 229 - 241.

Long AF, Kneafsey R, Ryan J, Berry J. 2002. The role of the nurse the multi-professional rehabilitation team. Journal of Advanced Nursing 37: 70-78.

Østerås N, Risberg MA, Kvien TK, Engebretsen L, Nordsletten L, Bruusgaard D, Schjervheim UB, Haugen IK, Hammer HB, Provan S, Øiestad BE, Semb AG,

Reis JG, Gomes MM, Neves TM, Petrella M, Ribeiro de Oliveira RD, Carvalho de Abreu DC. 2014. Evaluation of postural control and quality of life in elderly women with knee osteoarthritis. Revista Brasileira de Reumatologia 54: 208 - 212.

525 Suri S, Walsh DA. 2012. Osteochondral alterations in osteoarthritis. Bone 51: $204-211$. 
526 Sierakowska M, Doroszkiewicz H, Nyklewicz W, Mojsa W. 2010. Recommendations of the 527 European League Against Rheumatism - implications for nursing care. Problemy 528 Pielegniarstwa 18: 232-238. (Polish)

529 Sierakowska M, Sierakowski S, Wróblewska M, Krajewska-Kułak E. 2010. Health problems 530 of patients with osteoarthritis and their impact on the health related quality of life. 531 Rheumatology 48: 372-379. (Polish)

532 Sierakowska M, Doroszkiewicz H, Markowska A, Lewko J, Krajewska-Kułak E. 2014. Factors determining satisfaction of elderly people's caregivers with the home care they provide. Progress in Health Sciences 4: 82-87. (Polish)

Tak SH, Laffrey SC. 2003. Life satisfaction and its correlates in older women with osteoarthritis. Orthopaedic Nursing 22:182- 189.

Thorsen H, Hansen TM, Mc Kenna SP, Sorensen SF, Whalley D. 2001. Adaptation into Danish of the Stanford Health Assessment Questionnaire (HAQ) and the Rheumatoid Arthritis Quality of Life Scale (RAQoL). Scandinavian Journal of Rheumatology 30: 103 DOI: 10.1080/03009740151095402.

Wiland P, Madaj M, Szmyrka - Kaczmarek M. (ed.) 2008. Monitorowanie stanu pacjenta w chorobach reumatycznych. (Monitoring of patients state in rheumatic diseases). Wydawnictwo Medyczne, Wrocław. (Polish)

Wilmańska J, Gułaj E. 2006. Coincidence of arthrosis and depression in elderly patientstherapeutic implications. Ortopedia Traumatologia Rehabilitacja 6: 686 - 692. (Polish) 
549 and knee osteoarthritis, part II; OARSI evidence based expert consensus guidelines. $550 \quad$ Osteoarthritis and Cartilage 16: 981-1000 DOI: 10.1016/j.joca.2007.12.013. 